\title{
O VIRTUAL: destino da ontologia de Gilles Deleuze
}

\author{
The virtual: destiny of the Gilles \\ Deleuze's ontology
}

\author{
Eladio Craia \\ Doutor de Filosofia pela Unicamp, Professor da Pós-Graduação em Filosofia da PUCPR, \\ Cuririba, PR - Brasil, e-mail: eladio.craia@pucpr.br
}

\section{Resumo}

O presente texto, no seu primeiro movimento, organiza de modo sumário e cartográfico os principais conceitos da ontologia de Gilles Deleuze, como são: Diferença, univocidade, imanência e complexo questão-problema. Este movimento objetiva expor a centralidade da interrogação sobre o estatuto da Diferença, dado que, para Deleuze, esta não pode ser postulada nem como coisa, nem como nada. Num segundo momento, o trabalho especifica a importância da noção de "virtual-atual” para pensar a natureza da Diferença, expondo a matriz bergsoniana desta reflexão de Deleuze. Neste ponto o texto se demora na análise do estatuto do virtual segundo é pensado por Deleuze, opondo-o às noções anteriores de potência-ato e possível-real. Finalmente, como consideração provisória, o artigo propõe reconhecer o virtual como o conceito-chave para organizar a ontologia deleuziana.

Palavras-chave: Deleuze. Ontologia. Diferença. Univocidade. Virtual. 


\section{Abstract}

The present text, in it first movement, organize in a cartographic way the mains concepts of the Gilles Deleuze's ontology, like: Difference, univocity, immanence and question-problem complex. The objective of this movement is to expound the centrality of the interrogation about the nature of the Difference, given that, for Deleuze, the Difference can not be think neither thing nor nothing. In a second movement, the work point to the importance of the notion of "virtual-actual" to think the Difference's nature, showing the origin of this deleuzian's reflection in the philosophy of Bergson. In this moment the text analyses the concept of virtual, in the thought of Deleuze, in opposition with the previous concepts of act-potency and possible-real. Finally, as a conclusion, the paper propose recognize the virtual as the key concept to organize the ontology of Deleuze.

Keywords: Deleuze. Ontology. Difference. Univocity. Virtual.

\section{INTRODUÇÃO}

Transcorre hoje em certos setores da comunidade filosófica devota das análises da filosofia francesa contemporânea, uma polêmica que só na aparência é superficial. Trata-se daquela controvérsia em torno da possibilidade à pertinência e à fertilidade, ou não, de pensar uma ontologia na filosofia de Gilles Deleuze. ${ }^{1}$ Observando com mais detalhes este debate, podemos verificar que ele possibilita a formulação de uma questão maior: quais são a sorte e o destino da reflexão ontológica na contemporaneidade filosófica? Isto é assim porque nenhum outro pensador da segunda metade do século XX abordou com tanto vigor renovador as questões que, em diversos momentos da tradição filosófica, foram chamadas de ontológicas, quanto o fez Gilles Deleuze. Ora, o decisivo é que o pensador francês fez isto a partir de uma rica produção de conceitos; assim, sua

1 Os antagonistas são conhecidos, e ilustres, podemos indicar, a modo de metáfora dos vários agentes da discussão, dois nomes próprios; assim, devemos indicar e acompanhar a ZOURABICHVILI François; BADIOU, Alain; nesta polêmica. Em particular nos textos: O vocabulário Deleuze, e Deleuze o clamor do ser, respectivamente. 
eventual ontologia interroga as noções da tradição ao mesmo tempo em que propõe novas ferramentas para a reflexão, visando ajustar cada vez mais o foco da própria investigação ontológica. $\mathrm{O}$ texto que aqui apresentamos se organiza de modo geral na trilha de um destes novos conceitos: “o virtual”.

Como toda polêmica, esta que aqui invocamos também demanda uma primeira declaração a visa de gesto deflagrador, uma decisão conceitual entendida como uma escolha de grupo, - ou de bando filosófico-; eis nossa proclama: Deleuze postula uma ontologia. Dita ontologia é uma das mais ricas em densidade e rigorosidade especulativa, bem como uma das mais prolíficas em consequências filosóficas dos últimos anos. Poder-se-ia dizer que a ontologia deleuziana acrescenta uma nova dimensão reflexiva à recaracterização da interrogação pelo estatuto do Ser, - e, portanto de toda a preocupação ontológica, operada na filosofia do século XX.

Desde um ponto de vista amplo, podemos indicar que Deleuze pensa e afirma, ontologicamente, a Diferença pura e originária. Isto quer dizer que, do que se trata é de montar o tecido conceitual e problematizante que permita pensar o aparecimento e a atuação da Diferença. Esta proposta deleuziana se inscreve na jornada maior de grande parte da filosofia contemporânea, isto é, no intento de superação do pensar metafísico, historicamente organizado na tradição em torno das figuras centrais da essência e do fundamento. Assim, e em termos absolutamente gerais, podemos dizer que o norte deleuziano aponta para o pensamento de uma ontologia "não metafísica".

Ora, uma ontologia da afirmação da Diferença, que, enquanto tal, pretende abandonar as formas do pensamento identitário, demanda, para deixar de ser uma brumosa declaração de princípios, operadores conceituais concretos e específicos. Os conceitos principais que Deleuze mobiliza na organização desta reflexão são: a imanência, a univocidade, a expressão ontológica, e o problema filosófico.

O objetivo mais específico do presente texto é mostrar como o itinerário reflexivo da ontologia deleuziana, alicerçados nestes conceitos, aponta para o surgimento de um problema decisivo: a natureza virtual da Diferença.

\section{Deleuze: uma ontologia de nossos dias}

Sem perder a perspectiva da complexidade intrínseca da ontologia deleuziana, é possível indicar, de modo resumido, os principais movimentos reflexivos que balizam seu horizonte. 
O ponto de maior densidade especulativa é aquele que afirma que o Ser é Diferença, e que este Ser é unívoco, bem como imanente ao universo dos entes nos quais se expressa, não podendo operar, portanto, como fundamento, no sentido metafísico. Deste modo, para que o Ser possa, efetivamente, ser Diferença, é preciso que este se diga em um só sentido; mas, por sua vez, esta voz única deve ser a voz da própria Diferença absolutamente primeira. Por outro lado, visando não estabelecer hierarquias ou privilégios, - movimentos caros à metafísica, Deleuze reconhece a necessidade de demonstrar como o próprio Ser é imanente aos entes, e não mais transcendente ou eminente com respeito a eles.

Este é, então, o primeiro bosquejo: o Ser é unívoco enquanto Diferença e imanente aos entes nos que se diz. Neste ponto, uma outra categoria é postulada para poder avançar na reflexão. Deleuze afirma que qualquer configuração ou modo de ser dos campos fenomênicos, isto é, o mundo do aparecer das coisas, é multiplicidade atravessada por devires, que, por sua vez, podem ser nomeados de "fluxos de intensidade". Com relação a isto, é preciso frisar que a própria Diferença sempre é uma diferença intensa, uma pura potência vazia de conteúdo específico ou determinável. Ora, a intensidade é, justamente, aquilo que flui, que varia e que muda, que não pode parar em um lugar fixo, já que vive "se diferenciando" das outras intensidades e dela própria. Para Deleuze, a intensidade é sempre diferença de intensidade, e é inconcebível de outra maneira, sob o perigo de ser identificada, de modo forçado, com pontos fixos o estados já plenamente determinados. A intensidade, - os fluxos de intensidade-, não pressupõem, (e muito menos precisam), de um "suporte" ontológico, algo que seja predicável ontologicamente. Assim, - parafraseando o clássico exemplo da ontologia franciscana-, não se acrescenta uma intensidade de temperatura "à temperatura neutra" para "qualificá-la e defini-la”; pelo contrário, a temperatura é a sua diferença de intensidade. No interior da diferença de intensidade há um “diferencial” que a opera constantemente, mas que não é, por sua vez, um momento primeiro e privilegiado nem um "sopro de ser" animando a intensidade. Trata-se, contudo, da própria intensidade auto diferenciada acompanhada, sempre, do seu "ser diferença", que se detém no momento em que o faz a outra. Assim, o Ser é unívoco enquanto as singularidades do existente são multiplicidades abertas e intensas.

Finalmente, um outro eixo deve ser agenciado a este esquema. Com efeito, é preciso expor como é possível abordar, - de um modo propriamente filosófico, isto é, sob o modo da abertura questionadora-, o Ser-Diferença. Quanto a isso, a tarefa é a de pensar e desdobrar o complexo questão-problema, único horizonte reflexivo legítimo, segundo Deleuze, para abordar a problemático do Ser. 
Nenhum dos momentos indicados neste breve quadro de situação sobreviveria sem os outros. Estes se pressupõem e se determinam mutuamente. Da mesma forma, mostram e organizam aquele espaço que, desde o princípio, pretendíamos ler: o horizonte ontológico deleuziano.

Enfim, este horizonte se completa com um princípio caríssimo para Deleuze, presente ao longo de toda sua obra: a "afirmação ontológica”. Esta afirmação indica que o "Ser não é coisa", mas nunca é "Nada". ${ }^{2}$ Deste modo devemos analisar o "Ser deleuziano", supondo-o livre tanto de dualidades metafísicas quanto de negatividades ou carências. O Ser não precisa de nada com que se comparar, - ou com que seja comparado-, e muito menos precisa “daquilo que não é ele", para fundar algo assim como um "movimento ontológico". Tal movimento, para Deleuze, não existe, e tampouco existe um salto do "nada" ao Ser, mas sim expressão, como dinâmica interna ao próprio Ser. Deste modo nos encontramos perante duas hipotecas teóricas que Deleuze aceita honrar. A primeira é de sua própria safra: a Diferença não pode ser negativizada, ela deve ser pensada de forma afirmativa e produtora, não como ausência, falta, carência ou vazio nadificante. A segunda hipoteca e de cunho heideggeriano: a Diferença, (o Ser), não pode ser “ontificado”, isto é, substancializado, postulado como um existente, - seja sob a configuração que for.

Assim, este breve esquema da ontologia deleuziana nos coloca frente a um primeiro e desafiador interrogante: o que é aquilo que não é nem ente nem nada? Como é possível não ser coisa nem ausência de coisa? ${ }^{3}$

\section{$O$ encontro entre a diferença e o virtual}

A afirmação do Ser unívoco como Diferença pura e primeira, que se expressa segundo a configuração da imanência na multiplicidade dos entes, marca um ponto sem retorno; desde esta situação, só é possível avançar ainda mais na ontologia deleuziana, para não correr o risco de cair na mais neutra abstração

2 Embora o pensamento e a pergunta acerca do Nada sempre tenham acompanhado o questionamento a respeito do Ser, nós não os incluiremos em nosso estudo. Reconhecido o valor em chave ontológica que na "história da filosofia" foi atribuído ao problema do Nada, a exclusão que realizamos somente pode ser justificada em termos de espaço e recorte. De qualquer modo, esta problemática encontra-se melhor estudada no nosso artigo "O niilismo e sua sombra”, Temas e Matizes n. 1; Cascavel, 2002.

3 Propomos uma análise mais detalhada do horizonte ontológico deleuziano em nosso texto de CRAIA, 2002. 
conceitual. Este ponto sem retorno é atravessado por duas linhas reflexivas de igual importância para o reconhecimento da ontologia que aqui resumimos.

Uma das linhas especula sobre a forma de "pensar" esta estrutura ontológica ${ }^{4}$. A outra linha converge para a noção de virtual, reconhecida como peça chave para entender o estatuto da própria Diferença. É esta segunda linha a que propomos trabalhar a continuação.

Deste modo, o que para nós se encontra em pauta aqui, é o problema do virtual e seu agenciamento com a ontologia da Diferença.

Comecemos com uma primeira hipótese. A noção de virtual em Deleuze adquire um estatuto novo que a aloca no horizonte da ontologia. Na filosofia deleuziana o virtual tem menos a ver com as ciências, com a ética ou com a política, que com a pura pergunta pelo Ser. "Pois a igualdade entre o ser e a diferença só será exata se diferença for diferençação [...] e se, a partir de um virtual que, sem ser atual, possui, enquanto tal, uma realidade intensiva [...]” (ALLIEZ, 1996, p. 20).

No que segue, verificaremos a fertilidade desta estrutura conceitual.

Deixando momentaneamente de lado a abrangência que o conceito de virtual tem em nossos dias, ${ }^{5}$ o ponto de partida deleuziano para discutir a noção de virtual e atual e aquele traçado pelos conceitos aristotélicos de "potência e ato", e pelas noções medievais de "possível real”. Com efeito, Deleuze inclui explicitamente sua reflexão sobre o par virtual-atual na mesma linhagem interrogativa destes conceitos. Para Deleuze, potência-ato e possível-real, são noções que interrogam questões ontológicas, não físicas, gnosiológicas, éticas ou dinâmicas. O que se encontra em relevo nestas reflexões, e o "problema do devir”, isto é, da mudança ontológica, não do movimento ou dos deslocamentos fáticos dos entes. Para expor esta análise nos centraremos no problema medieval do possível-real e sua vinculação com a questão do virtual. ${ }^{6}$

4 Visando aprofundar a reflexão que se recorta com relação ao problema da possibilidade da abordagem, desde o pensar, do Ser-Diferença, seria necessário acompanhar a Deleuze nas suas considerações em torno do estatuto do problema filosófico e a questão ontológica. Reconhecemos a importância decisiva desta esfera conceitual para melhor organizar a problemática aqui desarrolhada, mas, no presente texto, por razões de foco e de espaço, interro garemos o segundo dos eixos indicados e deixamos para outra oportunidade a análise do estatuto do problemático em Deleuze.

5 Um estudo detalhado sobre a complexidade semântica da categoria do virtual neste inicio de milênio, bem como uma análise de sua importância nos deixaria demasiado distantes de nosso interesse específico. De qualquer sorte, reconhecemos a necessidade de um trabalho deste tipo desde o âmbito da filosofia.

6 Seria perfeitamente viável, - e necessário-, interrogar também a leitura que Deleuze propõe em torno da questão da potência e do ato aristotélicos. Por questões de espaço e de consistência de nosso texto, deixamos esta análise para outra oportunidade. 
Com efeito, é possível encontrar já na Idade Media uma primeira caracterização do virtual de vital importância para nós, por tratar-se da primeira abertura a esta problemática de um modo direito. Contando com a ajuda de uma etimologia sumária, podemos conferir que a palavra virtual vem do latim virtualis que se relaciona, por sua vez, da voz virtus, que, entre outras significações mais obvias, também carrega o sentido de força ou potência. Esta abordagem etimológica, eventualmente correta, é, sem dúvidas, insuficiente; é preciso reconhecer e especificar ainda que a palavra virtus é formada pelo prefixo vir, que indica o masculino, o penetrante, o que "informa", o que detém e comunica a forma. O destino ou objetivo dessa força que informa a forma nos conduz a um dois problemas centrais da filosofia do medievo. Para a filosofia medieval, o virtual é aquilo que está em potência, que ainda não foi atualizado. Assim sendo, o virtual parece necessitar de uma passagem na qual, ao mesmo tempo, se completa e desaparece. Com efeito, quando o virtual (ou potencial) é atualizado, ele deixa, literalmente, de "ser aquilo que era", para tornar-se outra coisa; sua natureza muda, o ser virtual se perde no surgimento do ser atual. Ora, se isto é assim, a forma informada na força do virtual é transferida ao ser atual e, portanto, a virtualidade constitui-se no núcleo de qualquer atualidade. Deste modo, o virtual entra em um tipo particular de relação com aquilo que dele difere, com aquilo que não é, ainda, informado e formado, em uma espécie de comércio da força e da forma. $\mathrm{O}$ fato de que o virtual venha a desaparecer naquilo que ele promove, e ao qual presta sua mais íntima natureza, é mais uma das astúcias da ontologia.

Nesta apertada resenha é possível ver como o virtual, apesar de possuir uma potência ontológica própria, é colocado pela escolástica no lugar da negatividade ou do quase-ser. Mas, - e apesar de não existir na filosofia do medievo uma negação do virtual em relação ao seu próprio ser-, tudo sugere que subsiste certa diminuição a respeito de seu estatuto ontológico. Parece que, entando virtual, este modo de ser contém um tipo de indeterminação, um “vir a ser”, uma categoria de ser que ainda não é um "sendo" pleno, e que reclama, para atingir sua completude, o estatuto do atual. Ora, esta concepção, herdada do aristotelismo e redefinida na filosofia escolástica, nos mostra, ao mesmo tempo, que a chave para ler este obscurecimento da natureza do virtual é justamente sua matriz aristotélica, sua identificação deste com o potencial, com a "pura potência". Esta espécie de hierarquização entre o potencial e o atual remete a outra hierarquização, - e com a qual está intimamente relacionada-, entre o “possível e o real”. É esta distinção a que se encontra no fundo da oposição entre potencial e atual, e que, secretamente, rege a sua lógica. A dinâmica desta relação indica que o possível não é ainda real, pois só o totalmente atualizado é absolutamente real, e o possível 
contrariamente, não é mais que um ser que não possui, ainda, sua existência concreta e determinada. De igual modo, o virtual possui uma face de mera possibilidade, pois certo aspecto dele não foi ainda atualizado, e, portanto encontrase mais perto do par potencial-possível que do atual-real. Baseado nesta última distinção que indicamos, (a distância entre o possível e o real), uma grande parte do pensamento filosófico aceitou a ideia da "irrealidade" do virtual, entanto que ele é, também, um “mero” possível, e não um ser atual e, portanto, não merecedor do estatuto do real pleno.

Assim sendo, Deleuze enfrenta um duplo trabalho, primeiro extrair o virtual da sombra de certa irrealidade ou não-ser, isto é, do lastro da negatividade; e segundo definir, de um modo tético e positivo o próprio virtual enquanto tal. É preciso, em suma, resgatar a positividade que em nossos dias possui a força do virtual. Neste sentido, propõe Pierre Lévy:

[...] defender uma hipóteses diferente, não catastrófica: entre as evoluções culturais em andamento nesta virada do terceiro milênio [...] exprime-se uma busca de hominização. [...] Ora, a virtualização constitui justamente a essência, ou ponta fina, da mutação em curso. Enquanto tal, a virtualização não é nem boa nem má, nem neutra. Ela se apresenta como o movimento do "devir outro" -ou heterogênese- do humano (LÉVY, 1996, p. 12).

Dando um passo a mais nesta direção, podemos constatar que a investigação que Deleuze propõe do registro ontológico, - de um modo afirmativo e multiplicador para sua própria filosofia -, vinculado ao problema do virtual aparece pela primeira vez de modo estricto nos estudos sobre Bérgson (DELEUZE, 1956, p. 77-122). Com efeito, em Bérgson, Deleuze encontrava a formulação de um puro Ser, como memória ontológica virtual. Um Ser simples, entanto que memória pura e, o que é mais interessante, um Ser que não é indiferente ou abstrato. Ora; que implica esta descoberta deleuziana em Bérgson? Responder a este interrogante exige que nos demoremos na leitura que Deleuze constrói em torno da própria obra bergsoniana.

Em termos ontológicos, não parece exagero afirmar que a interrogação ontológica deleuziana nos conduz à célebre tese de Bérgson que declara a natureza inconsciente e a-psicológica da memória, tese que Deleuze retoma em vários momentos da sua obra. Esta afirmação bergsoniana postula que o passado se conserva nele mesmo, e que não depende de uma consciência determinada que operasse como suporte, para poder existir. Trata-se de um 
passado puro, ontológico, enquanto conservação do Ser. "Colocamo-nos inicialmente, diz Bérgson, no passado em geral: o que ele assim descreve é $o$ salto na ontologia. Saltamos realmente no ser, no ser em si, no ser em si do passado” (DELEUZE, 1966, p. 44).

Por esse motivo, as "lembranças" desta memória ontológica não podem ser vividas psicologicamente sem serem tergiversadas. Quando uma lembrança é "trazida” para o presente, isto implica misturá-la com certo grau de percepção sensível individual e consciente. Assim, a lembrança que se torna conteúdo psicológico de uma consciência e, portanto, elemento de uma representação subjetiva que a falseia e deforma necessariamente, difere por natureza de uma memória como determinação ontológica pura do passado. Bérgson instaura assim, uma espécie de dualismo, - no qual Deleuze não vê nenhum vestígio concreto de metafísica-; de um lado, o presente, que corresponde à percepção e que constantemente segue e devêm mecanicamente, segundo mudem as circunstâncias fenomênicas singulares. Este presente não se conserva a si mesmo, e por tal motivo deve, permanentemente, ser re-produzido, o qual, falando em sentido ontológico pleno, de alguma maneira indica que não pertence ao Ser em $s i$. Por outro lado, Bérgson postula o passado, autêntica natureza do Ser que se conserva a si mesmo como memória ontológica que jamais devêm, e que, literalmente é aquilo que é. Assim sendo, a memória psicológica, enquanto conjunto de imagenslembranças opõe-se à memória ontológica que contém, nela mesma, todo o passado, isto é, todo o Ser, e que não pode ser relembrada de modo consciente. Trata-se, no fundo, da dualidade estabelecida pela matéria e a memória.

Entre a matéria e a memória, entre a percepção pura e a lembrança pura, entre o pressente e o passado, deve haver uma diferença de natureza, [...] Se temos tanta dificuldade em pensar uma sobrevivência em si do passado, é porque acreditamos que o passado já não é, que ele deixou de ser. Confundimos, então, o Ser com o ser-pressente. Todavia, o pressente não é; ele seria, sobretudo puro devir, sempre fora de si (DELEUZE, 1966, p. 42).

Estes dois registros são nitidamente diversos, mais isto não implica que, a priori, se deva outorgar mais realidade a um ou a outro. A matéria, enquanto mens momentanea da percepção do pressente, é plenamente atual, e designa a própria forma constitutiva da atualidade e da presença; por outro lado, a memória é real, mas não atual, portanto, o tipo de realidade que the corresponde é a virtualidade. 
Trata-se de sair da psicologia; trata-se de uma Memória imemorial ou ontológica. É somente em seguida, uma vez dado o salto, que a lembrança vai ganhar pouco a pouco uma existência psicológica: 'de virtual, ela passa ao estado atual [...]’. Fomos buscá-la ali onde ela está, no Ser impassível, e damos-lhe pouco a pouco uma encarnação, uma ‘psicologização’. [...] Verdadeiro salto no Ser (DELEUZE, 1966, p. 44).

Ora, Bérgson reconhece um tempo depois, sobretudo a partir do texto A Evolução criadora, não a simples existência dessimétrica do presente e do passado, mas a coexistência dessimétrica do passado com ele mesmo em níveis diferentes, sob o signo do virtual. Surge assim em Bérgson a ideia de uma memória-contração, ela mesma ilimitada, de todos os instantes do passado. Nasce deste modo, a recordada imagem da memória como cone invertido, figura esta que tenta exprimir ou esquematizar o acontecimento deflagrado pela afirmação de que a memória não contém “só um” passado, mas uma multiplicidade indefinida de passados, segundo os graus de concentração ou dilatação em que se tome o cone; por fim, e este é nosso centro, todos estes passados coexistem de modo virtual. Assim, o presente seria o grau mais contraído e condensado do passado, aquela instância onde todas as percepções convergem em um único ponto, o vértice do cone. Partindo deste ponto começa a distensão ou a dilatação, o desdobramento que conduz até a base do cone da pura memória.

Entre o passado-memória e o presente-matéria se estabelece uma “coexistência” transversal, uma espécie de contemporaneidade aberrante, mas claramente afirmada pelo exercício cotidiano da memória psicológica.

Eis agora nosso problema: como vai a lembrança pura adquirir uma existência psicológica? - como vai esse puro virtual atualizar-se? Impõese a pergunta, pois um apelo parte do pressente. Damos o 'salto': instalamo-nos não só no elemento do passado em geral, mas em tal ou qual região, isto é, em tal ou qual nível, que, em uma espécie de Reminiscência, supomos corresponder às nossas necessidades atuais. (DELEUZE, 1987, p. 44).

[...] De qualquer maneira, vê-se a revolução bergsoniana: não vamos do presente ao passado, da percepção à lembrança, mas do passado ao presente, da lembrança à percepção (DELEUZE, 1966, p. 44).

É assim que se define um inconsciente psicológico distinto do inconsciente ontológico. Este último corresponde à lembrança pura, virtual, impassível, inativa, em si. O inconsciente psicológico representa o movimento 
da lembrança em vias de atualizar-se [...] Não há qualquer contradição entre essas duas descrições de dois momentos do inconsciente distintos. Mais ainda, todo o livro Matéria e memória é um jogo entre os dois, com consequências que devemos ainda analisar (DELEUZE, 1966, p. 44).

Em resumo, o pensamento de Deleuze se agencia com a letra de Bérgson para elaborar uma noção de virtualidade que abandona algumas dicotomias ancestrais da filosofia. O virtual não é mais abstrato que o atual, não é um Espírito ou uma Ideia que anima o material presente; do mesmo modo, ultrapassa a tendência a confundi-lo com o mero possível e desta maneira, curiosamente, o virtual bergsoniano-deleuziano faz jus à célebre argumentação kantiana que demonstra que o real e o possível possuem o mesmo conceito. Finalmente, o virtual não é um momento primitivo, nem é parte de uma evolução que procura o atual para atingir sua completude; pelo contrario, o virtual coexiste e acompanha o atual no seu desdobrar-se, e não é eliminado no advento da atualidade.

Assim, Deleuze nos leva, através da letra de Bérgson, até o ponto onde virtualidade e ontologia se encontram não só de um modo decisivo, mas, sobre todo, afirmativo.

Por fim, dando um passo a mais em relação a Bérgson, mas a partir dele, podemos recolocar a "fórmula" ontológica deleuziana de um modo mais preciso. O Ser é Diferença uma vez que difere de si mesmo, sem procurar nada com o qual comparar-se ou determinar-se como diferente: diferença interna e primeira entanto virtual. Quando o Ser se expressa, isto quer dizer que se atualiza, não parte de uma negatividade, dado que agora ele é postulado como virtual, o que implica uma absoluta realidade e, paralelamente, a dinâmica de atualização ela mesma, não é outra coisa mais que uma diferenciação. Deleuze recordava em (1956, p. 93) que a Diferenciação é o “[...] movimento de uma virtualidade que se está efetivando a si mesma.”Vemos que já aparece aqui uma primeira colocação que permite postular que o Ser somente pode ser Diferença, bem como unívoco, entanto que é um virtual em um incessante processo de se autoatualizar e de se autodiferenciar. É por isto que se torna possível relacionar, sem contradições, as multiplicidades enquanto registro das singularidades, com o Ser unívoco como último horizonte ontológico. ${ }^{7}$

Os sítios onde é possível reunir a ontologia e o virtual não se limitam aos trabalhos sobre Bérgson, ao contrário, se desenvolvem igualmente na monografia: Diferença e Repetição (1993, p. 269-285), bem como no estudo sobre Leibniz (DELEUZE, 1991, p. 99-103; 117-126). Também tem seu espaço de reflexão em (DELEUZE; GUATTARI, 1991, p. 111-127; 144-154). 


\section{O novo estatuto afirmativo do virtual}

Aprofundando nesta direção, podemos lembrar que Deleuze determina em Diferença e Repetição, o virtual de acordo com seguintes características: primeiramente, o virtual possui uma realidade plena, não implica uma dramática carência ontológica, nem uma inaceitável inconsistência lógica, por tal motivo, não sê-lo deve opor ao real, mas somente ao atual. Assim, o virtual não deve esperar ser atualizado para poder ser real, ao contrário, o processo de atualização se estabelece entre dimensões absolutamente reais $e$ imbricadas. Por outro lado, o virtual, sendo absolutamente real porem não atual, se articula necessariamente em torno ao seu próprio processo de “atualização", mas este processo é, por sua vez, em cada caso "diferente e singular", portanto o atual nada perde de sua singularidade, ao tempo que o virtual não se torna um universal abstrato. É preciso reafirmar, junto com Deleuze que, em termos referidos estritamente à dinâmica ontológica, seria um erro estabelecer que o virtual se encontre em constante oposição ao real, pois isso implicaria igualá-lo à passagem e a oposição que se opera entre o possível e o real, ora, é justamente deste esquema que o virtual deve ser tirado.

O possível e o virtual se diferenciam, incluso, porque o primeiro remete à forma da identidade no conceito (o real e o possível possuem o mesmo conceito), enquanto o segundo designa uma multiplicidade pura na Idéia, que exclui radicalmente o idêntico como condição previa. (DELEUZE, 1993, p. 338).

Estamos em condições agora de ajustar melhor os motivos pelos quais precisamos abandonar o esquema montado em torno da dualidade possívelreal exposta no ponto anterior, para reler o modo de ser virtual. Isto é assim, pois tanto o possível simples, quanto o movimento produzido na sua oposição com o real, encontram-se carregados de negatividade, uma vez que o possível, não sendo real, possui, como único modo de ser, a própria possibilidade; portanto, não passa de um não-Ser, isto é, uma forma do negativo, uma vez que sua própria postulação ontológica se baseia em não possuir, ainda, a plena realidade. Assim é para superar uma das formas da negatividade que Deleuze opõe ao par possível-real, a dinâmica estabelecida pela "relação" virtual-atual; trata-se de abandona a "dualidade" determinada pela carência de dignidade ontológica de uma dos pólos da própria dualidade. Novamente Lévy: "Em termos rigorosamente filosóficos, o virtual não se opõe ao real, mas ao atual: virtualidade e atualidade são apenas duas maneiras de ser diferentes” (LÉVY, 1996, p. 15). 
Trata-se de uma constante atualização das potências do virtual, que já são absolutamente reais. Não subsiste nenhuma dualidade, pois o atual já está no virtual, ou, melhor, a sua força de atualização, é por isso que não se opõem numa dualidade metafísica, ao contrário, se agitam numa dramatização que leva à própria atualização, seja em um estado de coisas, ou em uma potência do pensamento.

O virtual não se opõe ao real, mas só ao atual. O virtual possui realidade plena entanto virtual. [...] O virtual deve ser definido, então, como uma parte estrita do objeto real - como sim o objeto tivesse uma de suas partes no virtual [...].

[...] longe de ser indeterminado, o virtual está absolutamente determinado. [...] o virtual, pelo contrário, é característico da Idéia; é a partir da sua realidade que a existência se produz, e é produzida formalmente. (DELEUZE, 1993, p. 338-342).

Deste modo, as reflexões de Deleuze a respeito do virtual, operam nos dois registros que organizam a problemática ontológica. O primeiro referese ao horizonte puramente ontológico sobre o estatuto do Ser, enquanto que o segundo remete ao processo fático de "dramatização" onde o virtual se atualiza, e onde o processo de individuação se desenvolve. A importância da operatividade destes dois registros aparece claramente nesta citação.

A filosofia é a teoria das multiplicidades. Toda multiplicidade implica elementos atuais e elementos virtuais. Não há objeto puramente atual. Todo atual rodeia-se de uma névoa de imagens virtuais. Essa névoa eleva-se de circuitos coexistentes mais ou menos extensos, sobre os quais se distribuem e correm as imagens virtuais (ALLIEZ, 1996, p. 49).

Colocamos em jogo, até agora, as categorias de atualização e de dramatização, às quais devemos acrescentar agora a categoria de "realização"; todas elas indicam, sem dúvida, certo processo, um tipo de "dinâmica". No entanto, tais processos não são similares ou equivalentes entre eles. É preciso, então, revelar as particularidades de cada um, e as diferenças que entre eles existem. Indicamos anteriormente dois pares operativos denunciados por Deleuze: o par possível-real, e o par potencial-atual, a cada um destes pares correspondem um determinado processo. Assim, um possível pode vir a ser "realizado", mas entanto possível, nada muda nele no processo de realização. O passo da possibilidade para a realidade "só acrescenta a existência concreta e individual” ao possível, mas nada muda em sua determinação como mero 
possível: a chuva real não é mais que a chuva possível já realizada. Não existe criação na realização, pois nada de inovador é adicionado no processo, nem em termos de forma nem de "Ideia”. Já no caso do par potencial-atual, o processo estabelecido deve ser definido como uma "atualização", uma vez que algo “devém”, isto é, muda no próprio movimento de atualização. Atualizar é colocar em ato algo que ainda "não é” no seu estado de potencia, o mesmo que no modo atual, mas sem perder a relação interna necessária entre ambos, assim, na semente se encontra em potência a árvore. Semente e árvore não são o mesmo, mas o segundo momento só pode ser atualizado, se, e só se, há certa relação direta e reconhecida entre ambos os pólos, uma árvore só se encontra em potência em uma semente, e não em uma rocha. Ora, ainda neste esquema uma negatividade subsiste, pois nesta interpretação, como já foi dito, o virtual escolástico, dele se trata, não passa de um potencial, isto é, a árvore está “em potência” na semente e, se bem que uma coisa diferente se produza no processo, essa diferença é sempre regida pela "essência" da potência: parece claro que da semente se pode atualizar uma árvore, mas nunca um morcego. Para que o processo de atualização não seja simplesmente uma culminação das exigências de uma potência determinada, de "um ser em potência”, é preciso que se torne uma "dramatização". No caso da dramatização um virtual é, de igual modo, atualizado, ou seja, que uma diferença se acrescenta no advento do atual, mas essa diferença não devém, necessariamente, da essência de uma potência, mas do campo problemático de um virtual. Atualizar um virtual pelo processo de dramatização é, na verdade, atualizar um nó de problemas, um horizonte problemático. Atualizar por dramatização é colocar de modo atual uma solução determinada para um problema mantido como puro virtual, e não como potencial, em um nó problemático. Virar arvore é um dos "problemas da semente”, uma vez que a semente é um nó de problemas, mas o tipo de solução e o modo da dramatização não se encontram no problema.

A atualização aparece então como a solução que não estava contida previamente no enunciado. A atualização é criação, invenção de uma forma a partir de uma configuração dinâmica de forças e finalidades. [...] O real assemelha-se ao possível; em troca, o atual em nada se assemelha ao virtual: responde-lhe (LÉVY, 1996 p. 16).

Ora, não devemos confundir o sentido da expressão “solução" segundo esta é utilizada aqui, com o sentido habitual de solução entendida como re-solução de problemas gnosiológicos ou de conhecimento. Não se trata de esgotar um problema pela solução; a solução não elimina o problema. A solução, como aqui é 
pensada a partir de Deleuze, expressa e desdobra o problema em um campo fenomênico determinado. Aqui "solução" implica atualização e dramatização, correspondendo, portanto, diretamente ao âmbito ontológico e não gnosiológico.

É justamente este processo de dramatização o modo que Deleuze indica para recolocar o virtual na esfera da afirmação e da criação como caminho para um modo diferente de atualização.

[...] a atualização do virtual se faz sempre mediante diferença, divergência ou diferenciação. A atualização rompe tanto com a semelhança como processo, como com a identidade como princípio. Jamais os termos atuais se assemelham à virtualidade que atualizam: as qualidades e as espécies não se assemelham às relações diferencias que encarnam. A atualização, a diferenciação, neste sentido, é sempre uma verdadeira criação.

Atualizar-se [...] é sempre criar linhas divergentes que correspondem, sem semelhança, com a multiplicidade virtual. $\mathrm{O}$ virtual tem [...] um problema para resolver; é o problema o que orienta [...].

São os processos dinâmicos os que determinam a atualização, [...] são, nem mais nem menos que dramatizações: dramatizam o real. [...] a dramatização é a diferenciação da diferenciação, tanto qualitativa quanto quantitativa. (DELEUZE, 1993, p. 273-274).

Assim sendo, salienta-se outra característica principal do virtual: a sua constituição problemática. O virtual não delimita um espaço ao modo do fundamento, isto é o lugar do infundado, fixo e, então, ou totalmente determinado ou, pelo contrario, totalmente indeterminável. Do mesmo modo, não se constitui como o ainda inacabado, ou seja, não atualizado e, portanto, ontologicamente irreal; se assim fosse não passaria de um potencial simples, ou um mero possível cru. Dito mais especificamente, o virtual não é, nem irreal, nem fundamento; estatutos estes que podemos considerar como sintomas das interpretações clássicas. Pelo contrário, o virtual é um nó problemático de onde as atualizações em forma de dramatização surgem como criação, e não como destinação.

É preciso ressaltar que várias das categorias com as quais Deleuze opera permanentemente na sua reflexão devem ser abordadas desde o vetor especulativo do virtual. A intensidade como diferença pura, as relações e as contrações-hábitos que aparecem no texto sobre Hume, os blocos de espaçotempo que habitam, entre outras obras, $O$ que é a Filosofia? e Diferença e Repetição, todas elas possuem uma realidade virtual. Isto não implica que as mesmas sejam anuladas no processo de atualização, o virtual não finaliza onde começa o atual, mas, contrariamente, se relacionam sem uma lógica da oposição e sem um princípio de identidade sensível. 
Como indica o próprio Deleuze, em $O$ virtual e o atual, todo objeto, bem como todo individuo ou toda singularidade, possuem duas metades incompossíveis: a metade virtual e metade atual. É na região virtual onde encontramos todas as facetas sub-representativas, a-subjetivas e pré-individuais, enquanto campo problemático da Diferença. Assim, podemos pensar as multiplicidades e seus devires longe da oposição do múltiplo e do Uno; contrariamente, nos abrimos à possibilidade de pensar a multiplicidade como realidade substantiva, além da disjunção entre Ser e Devir.

Finalmente, revela-se a profunda relação ontológica entre o virtual, a Diferença, e o terreno da questão-problema filosófico. Com efeito, é através do virtual que o problema pode ser autodeterminado como multiplicidade e que a própria Diferença, enquanto Ser unívoco pode ser pensado sem vestígios de unidade.

\section{CONCLUSÃO}

No seu programa de elaboração de um pensamento do Ser como Diferencia primeira, nem substancializável nem negativizada, Deleuze propõe uma Diferença unívoca e imanente que, enquanto autodiferenciação é uma pura intensidade. Isto implica uma dinâmica que não é a dos entes, mas do devir como produção desta própria diferença a partir de seu diferencial de intensidade. Como vimos anteriormente, o problema deste esquema é que, enquanto devir, isto é, mudança em chave ontológica, a Diferença deve ser pensada fora da passagem de um não ser a um ser, ou de um conjunto de predicados e categorias para outro diferente. Isto implicaria recair nas formas da fundamentação baseadas no nada; ou seja, aquilo que não era começa a ser e vice-versa. Para evitar este problema Deleuze esboça uma outra natureza para a Diferença: a virtualidade. A diferença pode pertencer ao devir sem se manter amarrada a fundamentação da passagem do que não é para o que é, porque o virtual, isto é, a natureza da própria Diferença já é absolutamente real. Trata-se do devir ontológico postulado entre formas da realidade, já que o atual não é mais que uma expressão do virtual como dimensão real.

Com esta estrutura Deleuze pretende superar a aporía que implicaria pensar uma Diferença primeira que, ao mesmo tempo, deve ser proposta como atravessada pela negatividade.

O Ser-diferença pode ser unívoco porque sua natureza e a virtualidade, que permite, ao mesmo tempo, constituir multiplicidades não 
fechadas ou estabilizadas, e produzir uma expressão ontológica como dinâmica de singularização dos entes ou dos campos fenomênicos de aparecimento. Sua dimensão de ente pertence ao atualizado, e sua potência enquanto Ser ao virtual. Nem coisa nem nada: virtual, destino de todos os devires.

\section{REFERÊNCIAS}

ALLIEZ, E. Deleuze filosofia virtual. Rio de Janeiro: 34 Literatura S/C, 1996.

CRAIA, E. A problemática ontológica em Gilles Deleuze. Cascavel: EDUNIOESTE, 2002. "O niilismo e sua sombra”. In: . Temas e matizes, n. 1. Cascavel: EDUNIOESTE, 2002.

DELEUZE, G. La conception de la différence chez Bergson. In: MICHEZ. Albin. Les études bergsoniennes. Paris: Albin Michel, 1956. v. 4, p. 77-122.

. Le bergsonisme. Paris: PUF, 1966.

A Dobra-Leibniz e o barroco. Campinas: Papirus, 1991.

Différence et répétition. Paris: PUF, 1993.

DELEUZE, G; GUATTARI, Felix. Qu'est-ce que la philosophie? Paris: Les Éditions de Minuit, 1991.

LÉVY, P. O que é o virtual? São Paulo: Ed. 34, 1996.

ZOURABICHVILI, F. O vocabulário de Deleuze. Rio de Janeiro: Relume Dumará, 2003.

Recebido: $13 / 11 / 2008$

Received: $11 / 13 / 2008$

Aprovado: 22/12/2008

Approved: $12 / 22 / 2008$

Revisado: 05/10/2009

Reviewed: 10/05/2009 